\title{
Pneumonia Due to Influenza A/H1N1 2009 in Patient With Renal Transplant: A Case Report
}

\author{
Yasemin Usul Soyoral ${ }^{\mathrm{a}, \mathrm{e}}$, Mehmet Tasdemir ${ }^{\mathrm{b}}$, Cengiz Demir ${ }^{\mathrm{c}}$, Bulent Ozbay ${ }^{\mathrm{d}}$, \\ Huseyin Begenik ${ }^{\mathrm{a}}$, Reha Erkoc ${ }^{\mathrm{a}}$
}

\begin{abstract}
The 2009 pandemic H1N1 is a new virus. There is very little information related to the progression of the Influenza H1N1 2009 virus in immunosuppressive patients with a renal transplantation history. We presented the therapeutical management and clinical course of a patient who referred to our clinic because of pneumonia and respiratory failure due to Influenza H1N1 2009 virus and who received immunosuppressive therapy after renal transplantation.
\end{abstract}

Keywords: Renal transplantation; Influenza A H1N1 2009; Pneumonia

\section{Introduction}

The 2009 pandemic H1N1 is a new virus. Genetically, it is a mongrel, coming from three recognized sources (pigs, birds, and humans) which were combined in pigs [1]. In late March and early April 2009, an outbreak of H1N1 influenza A virus infection was detected in Mexico, with subsequent cases observed in many other countries [2]. On June 11, 2009, the World Health Organization raised its pandemic alert level to

Manuscript accepted for publication March 1, 2011

${ }^{a}$ Yuzuncu Yil University, Faculty of Medicine, Department of Nephrology, Van, Turkey

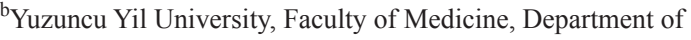
Internal Medicine, Van, Turkey

${ }^{c}$ Yuzuncu Yil University, Faculty of Medicine, Department of Hematology, Van, Turkey

${ }^{\mathrm{d} Y u z u n c u}$ Yil University, Faculty of Medicine, Department of Pulmonology, Van, Turkey

${ }^{\mathrm{e} C}$ Corresponding author: Yasemin Usul Soyoral,

Email: yaseminsoyoral@yahoo.com

doi:10.4021/jmc160w the highest level, phase 6 , indicating widespread community transmission on at least two continents [3].

The risk of developing complications in patients with a medical state of an underlying disorder such as asthma, chronic obstructive pulmonary disease (COPD), immunosuppression, diabetes, obesity or chronic cardiac disease and children below 5 and patients over 65 years of age and pregnant women is higher and may require immediate hospitalization [4]. Patients who require intensive care generally may have a lung graph compatible with a hypoxia state and acute respiratory distress syndrome [5]. There is very little information related to the progression of the Influenza H1N1 2009 virus in immunosuppressive patients with a renal transplantation history.

We have presented the therapeutical management and clinical course of a patient who referred to our clinic because of pneumonia and respiratory failure due to Influenza H1N1 2009 virus and who received immunosuppressive therapy almost 7 years ago after renal transplantation.

\section{Case Report}

A 35-year-old male patient who underwent renal transplantation in 2002 due to chronic renal failure with an unknown etiology referred to our emergency service because of symptoms as high temperature, shortness of breath, dry cough, sore throat and headache and diffuse muscle pain. The complaints of this patient began suddenly nearly 24 hours before his referral to our clinic. Patient was receiving cyclosporineA $2 \times 100 \mathrm{mg}$, azathioprine $2 \times 50 \mathrm{mg}$ /day, prednisolone $1 \mathrm{x}$ $10 \mathrm{mg} /$ day, doxazosin $2 \times 4 \mathrm{mg} /$ day, diltiazem 1 x $60 \mathrm{mg} /$ day and amlodipine $1 \times 10 \mathrm{mg} /$ day at the time of his referral. Patient was highly confused during physical examination and showed the following findings: number of respiration: $32 /$ min, blood pressure: $170 / 110 \mathrm{mmHg}$, temperature: $38.8^{\circ} \mathrm{C}$, pulse rate: $116 / \mathrm{min}$ and oxygen saturation: $83 \%$ at ambient air. Dermal turgor was reduced, the oropharynx was slightly hyperemic and rales were present at bilateral lung basals. Hearth beat was rhythmic and tachycardia was present.

Blood analysis revealed the following values: hemoglobin: 9.2 gr/dl, WBC: 9300/ $\mu$ l, Plt: $228000 / \mu 1$, blood sugar: 


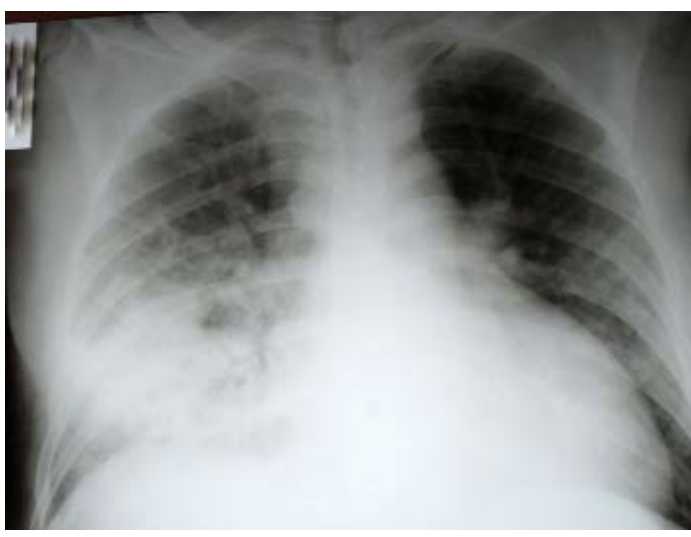

Figure 1. Chest X-ray at the time of ER admission.

$98 \mathrm{mg} / \mathrm{dl}$, urea: $67 \mathrm{mg} / \mathrm{dl}$, creatinin: $1.72 \mathrm{mg} / \mathrm{dl}$, AST: 18 U/L, ALT: 21 U/L, LDH: 392 U/L, CPK: 72 U/L, Na: 131 $\mathrm{mmol} / \mathrm{L}, \mathrm{K}: 3.4 \mathrm{mmol} / \mathrm{L}, \mathrm{Ca}: 8.2 \mathrm{mg} / \mathrm{dl}, \mathrm{P}: 4.3 \mathrm{mg} / \mathrm{dl}$ and CRP: $195 \mathrm{mg} / \mathrm{L}$. Urinalysis was normal. Chest X-ray showed diffuse ground-glass density consolidation at the lower zone of the right lung, and a minimal ground-glass density at the lower zone of the left lung (Fig. 1). The patient was immediately transferred to the intensive care unit with pneumonia possibly due to H1N1 virus, confused consciousness and low oxygen saturation. Patient was somnolent and temperature was $38.8^{\circ} \mathrm{C}$. Oseltamivir 2 x $75 \mathrm{mg}$, azithromycin $500 \mathrm{mg} /$ day and ceftriaxone $2 \mathrm{~g}$ /day were initiated. We reduced the dosage of an immunosuppressive agent, azathioprine to 50 $\mathrm{mg}$ and increased the dose of prednisolon to $15 \mathrm{mg}$. Oxygen saturation in ambient air was $85 \%$ with $5 \mathrm{~L} / \mathrm{min}$ nasal oxygen. We decided that there was no need for mechanical ventilation. Patient was followed up with nasal oxygen. However, acute renal failure developed during the stay at the intensive care unit and creatinine level increased to $2.7 \mathrm{mg} /$ dl. Urine output, hydration status and bio-chemical values of the patient were carefully monitored and necessary liquid and electrolyte therapies were provided. Cyclosporine level was at the therapeutical range (Co: $102 \mathrm{mg} / \mathrm{L})$. At day 5 in the intensive care unit, patient's general condition was moderately good, consciousness state was open, and the oxygen saturation in ambient air was $88 \%$. After administration of $3 \mathrm{~L} / \mathrm{min}$ nasal oxygen, oxygen saturation increased to $93 \%$. The following values were obtained: blood pressure: 140/90 $\mathrm{mmHg}$, pulse: $95 / \mathrm{min}$ and temperature: $37.2^{\circ} \mathrm{C}$. At day 7 , patient's condition state improved and oxygen saturation at ambient air was measured as $92 \%$ and chest X-ray lung graphs and renal functions turned to normal and the patient was transferred back to a normal room (Fig. 2).

Definitive diagnosis of H1N1 was confirmed after discharged from hospital by nasal swab result which was done by Refik Saydam National Public Health Agency, Virology reference and research laboratory, national influenza center. Influenza A (H1N1)v PCR was performed with Qiagen artus

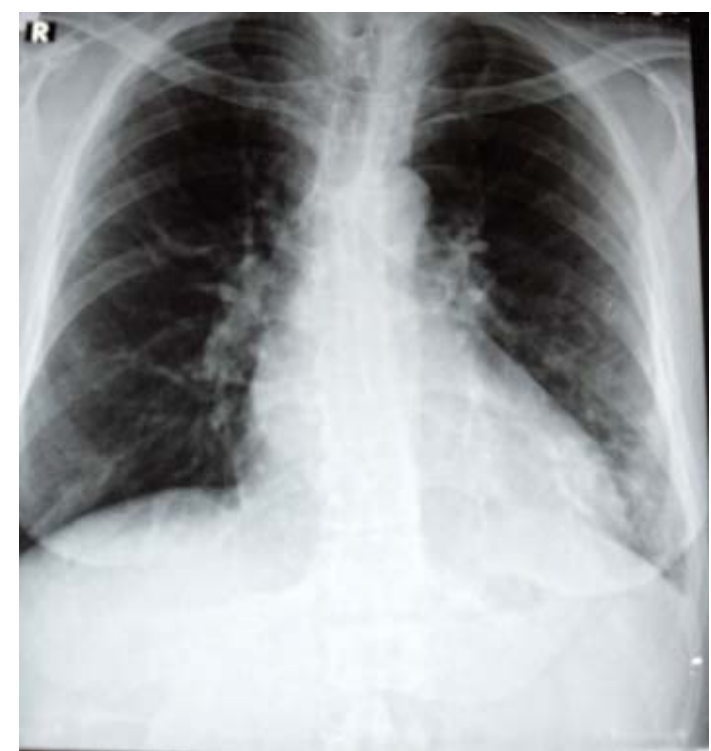

Figure 2. Chest $\mathrm{X}$-ray 7 days later.

InfL/H1 LC/RC RT-PCR commercial kit.

\section{Discussion}

Influenza A H1N1 2009 virus can spread out by direct contact as in seasonal flu and by the inhalation of infected airborne particles or by the means of droplet infection [6]. Typical clinical symptoms are fever, tremor, headache, coughing, a sore throat, myalgia and weakness. During the 2009 pandemic, it was reported that some patients experienced a rapidly progressive pneumonia, respiratory failure, acute respiratory distress syndrome and pulmonary emboli [7].

The patient presented in this article stated that his symptoms began 24 hours ago. Patient referred to our clinic with a pneumonia table. The clinical course was rapid and within 24 hours the patient was transferred to the intensive care unit. After onset of an early therapy regime, patient was discharged from the hospital within ten days due to a significant improvement in his general condition.

There are a small number of case presentations in the literature related to immunosuppressive patients with a developed H1N1 2009 virus infection after organ transplantation. Watcharananan et al [8] have reported the course of a H1N1 infection in two immunosuppressive patients. The first patient who underwent HD because of chronic rejection after renal transplantation and under low-dose maintenance steroid treatment referred to a clinic due to coughing and shortness of breath. An empiric therapy was initiated to this patient even though rapid antigen test was negative. Unfortunately, a few days later the patient's general condition worsened and oral oseltamivir therapy was initiated due to the sudden requirement for non-invasive ventilation. Clinic healing was 
observed and the patient was discharged from the hospital at Day 17. The other patient was receiving immunosuppressive agents due to renal transplantation and dyspnea developed at Day 2 after hospitalization to undergo a cataract operation. Considering the clinical status of the patient, oseltamivir $2 \mathrm{x}$ $75 \mathrm{mg}$ /day was immediately initiated even though the results of the rapid antigen test were negative. Eventually the dosage of oseltamivir was instantly increased. The patient was discharged 2 weeks later. Troppmann et al [9] reported a patient who referred to a hospital due to dyspnea and coughing complaints at Day 11 after renal transplantation. This patient failed to respond to treatment and died.

The rapid antigen test, direct fluorescent antibody test, PCR and culture test can be used in the diagnosis of influenza [10]. The $2009 \mathrm{H} 1 \mathrm{~N} 1$ virus is sensitive to neurominidase inhibitors such as oseltamivir [11]. According to the studies conducted, at an early stage antiviral treatment after infection may reduce the intensity and period of the disease and possibly provide early inhibition of the influenza virus replication as well [12]. Death reports related to the pandemic virus demonstrated the fact that delayed hospitalization and antiviral therapy were the main factors that may lead to a fatal result [13]. However, empiric therapy must be initiated in patients who are highly suspected to be infected by the virus based on their clinic table, even though results of tests are negative [14]. We preferred treating our patient with oseltamivir while PCR results were pending.

As a conclusion, symptoms of Influenza A H1N1 2009 virus in immunosuppressive patients may resemble healthy adults, however the clinic progression in immunosuppressive patients can be rapid and severe. In our case and as it is in other cases in the literature, 24 hours intensive care may be required. The success of early and high dose antiviral therapy is high and therefore starting therapy can be a lifesaving factor even though a clinical doubt is present and a solid confirmation is not yet provided.

\section{References}

1. Garten RJ, Davis CT, Russell CA, Shu B, Lindstrom $\mathrm{S}$, Balish A, Sessions WM, et al. Antigenic and genetic characteristics of swine-origin 2009 A(H1N1) influenza viruses circulating in humans. Science 2009;325(5937):197-201.

2. Outbreak of swine-origin influenza A (H1N1) virus infection - Mexico, March-April 2009. MMWR Morb Mortal Wkly Rep 2009;58(17):467-470.

3. World Health Organization. World now at the start of 2009 influenza pandemic. http://www.who.int/me- diacentre/news/statements/2009/h1n1 pandemic phase6_20090611/en/index.html (Accessed June 11, 2009).

4. Hospitalized patients with novel influenza A (H1N1) virus infection - California, April-May, 2009. MMWR Morb Mortal Wkly Rep 2009;58(19):536-541.

5. Intensive-care patients with severe novel influenza $A$ (H1N1) virus infection - Michigan, June 2009. MMWR Morb Mortal Wkly Rep 2009;58(27):749-752.

6. Maines TR, Jayaraman A, Belser JA, Wadford DA, Pappas C, Zeng H, Gustin KM, et al. Transmission and pathogenesis of swine-origin $2009 \mathrm{~A}(\mathrm{H} 1 \mathrm{~N} 1)$ influenza viruses in ferrets and mice. Science 2009;325(5939):484-487.

7. Agarwal PP, Cinti S, Kazerooni EA. Chest radiographic and CT findings in novel swine-origin influenza A (H1N1) virus (S-OIV) infection. AJR Am J Roentgenol 2009;193(6):1488-1493.

8. Watcharananan SP, Suwatanapongched T, Wacharawanichkul P, Chantratitaya W, Mavichak V, Mossad SB. Influenza A/H1N1 2009 pneumonia in kidney transplant recipients: characteristics and outcomes following high-dose oseltamivir exposure. Transpl Infect Dis 2010;12(2):127-131.

9. Troppmann C, Cohen S, de Mattos A, Perez R. Rapidly progressive lethal infection with novel influenza A (H1N1) 2009 virus in a kidney recipient: a cautionary tale. Transplantation 2010;89(3):369-370.

10. Ginocchio CC, Zhang F, Manji R, Arora S, Bornfreund M, Falk L, Lotlikar M, et al. Evaluation of multiple test methods for the detection of the novel 2009 influenza A (H1N1) during the New York City outbreak. J Clin Virol 2009;45(3):191-195.

11. Oseltamivir-resistant 2009 pandemic influenza A (H1N1) virus infection in two summer campers receiving prophylaxis--North Carolina, 2009. MMWR Morb Mortal Wkly Rep 2009;58(35):969-972.

12. Aoki FY, Macleod MD, Paggiaro P, Carewicz O, El Sawy A, Wat C, Griffiths M, et al. Early administration of oral oseltamivir increases the benefits of influenza treatment. J Antimicrob Chemother 2003;51(1):123129.

13. Perez-Padilla R, de la Rosa-Zamboni D, Ponce de Leon S, Hernandez M, Quinones-Falconi F, Bautista E, Ramirez-Venegas A, et al. Pneumonia and respiratory failure from swine-origin influenza A (H1N1) in Mexico. N Engl J Med 2009;361(7):680-689.

14. Chan KH, Lai ST, Poon LL, Guan Y, Yuen KY, Peiris JS. Analytical sensitivity of rapid influenza antigen detection tests for swine-origin influenza virus (H1N1). J Clin Virol 2009;45(3):205-207. 